\title{
It's up to us all to end child labour
}

Written by: Kailash Satyarthi, 2014 Nobel Peace Prize Laureate, Founder, Kailash Satyarthi Children's Foundation

Last update: 16 June 2016

A young boy named Kalu, who had been rescued from a carpetweaving unit in Bihar, once raised a compelling and very significant question when he met then-President Bill Clinton. In conversation with the president, Kalu politely inquired about his plans and policies with regard to the world's children and their condition. I remember distinctly Mr Clinton trying to explain to the boy that he had virtually served his tenure and would soon be replaced by someone else who, as president,would be in a more appropriate position to initiate actions and take responsibility. To which Kalu very sincerely asked, "Why do you have to be the president to do anything for children?"

\section{Kailash Satyarthi, 2014 Nobel Peace Prize Laureate, Founder, Kailash Satyarthi Children's Foundation}

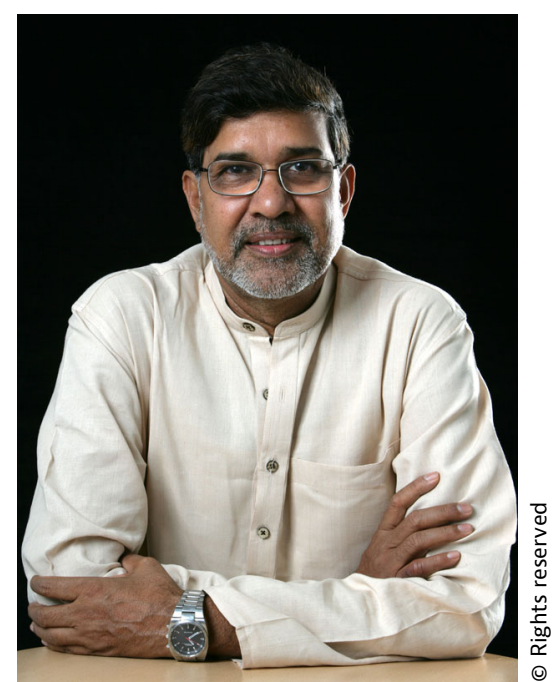

Kalu's question had an overwhelming impression on the president and the onlookers. I remember being completely astonished at the brilliance of the boy and his question, and being even more proud of the earnestness with which he had asked it. That question was not an appeal to the president alone. It was the question of every child who has been denied their basic rights to the entire world and it was Kalu who had raised it in that moment. 
Globally, 168 million children are employed in labour and 5.5 million are captive in modern forms of slavery; the rising refugee crisis is only adding to this predicament. Although there are no official figures on the employment of Syrian children in the Turkish garment industry, the number of child labourers employed by international brands is increasing.

According to a Tulane University survey, the number of children involved in hazardous activities in cocoa farming increased by $46 \%$ in Côte d'Ivoire between 2009 and 2014. Despite consistent efforts to combat this situation, there are still 2.1 million child labourers involved in the industry, usually working in hazardous conditions.

This survey is a follow-up to the 2001 Harking-Engel Protocol, which seeks to eliminate the worst forms of child labour in cocoa-growing countries. The agreement is a voluntary public-private partnership and lays out a series of actions, including the development of industry certification. However, due to extreme poverty, limited access to education and lack of monitoring, along with governments' needs to address other issues, proper enforcement of the law and recommended guidelines has not been possible.

During the first phase of my fight against child labour in the 1980s the world remained ignorant. There were 250 million children in labour then, but the issue of child rights was not a mainstream topic. Even though this number has decreased, there is far more work to be done and the role and centrality of the corporate sector cannot be overlooked.

To illustrate this, I will draw upon my own experience and share the story of Rugmark, now known as GoodWeave. To ensure there were no more children forced to be carpet weavers like Kalu, I started Rugmark in 1995 following intense discussions with carpet manufacturers, middlemen, exporters, NGOs in India and abroad and leading carpet importers in Germany and the US.

The idea behind Rugmark was to eradicate child labour in the carpet manufacturing industry with well-placed interventions in the supply and demand chains. I believed that after sparking the will for change the industry could be moved successfully from child-labour afflicted to child-labour free, and could help

I believed that after sparking the will for change the industry could be moved successfully from childlabour afflicted to childlabour free social development by disrupting the circle of poverty, illiteracy, poor health and illegal employment.

This initiative led to a decline in child labour in the carpet industries of South Asia from over a million child labourers in the 1990s to less than 200,000 today. The most remarkable fact of this endeavour is that there was no adverse effect on rug exports from South Asia to the West. In fact, there was more awareness amongst consumers about child labour in the carpet industry and exporters were able to 
strike better deals with buyers. Optimism amongst the stakeholders brought about a remarkable change that was channelled through the power and reach of the corporate sector.

Most innovations dreamt up in the industrial and information technology revolution have served only financial indicators. The condition of our children now demands the corporate sector to launch another revolution, with stringent social audits and ethical sourcing and trading. I firmly believe that the business community can put compassion alongside profit. Businessmen with compassionate hearts and businesses with compassionate intelligence should be the norm. We cannot hold the government solely accountable for the condition of our children. Also, we should not continually undermine our role in reforming society.

Innovation is an evolutionary process and to create a future more considerate of our children we need to think with more conviction and more creativity. To provide all children with an equal opportunity to realise their full potential innovation must not only benefit those who can afford it, but reach and meet the needs and rights of those who are the most marginalised and vulnerable.

Inclusive growth can only be accomplished with progressive and innovative methods. That means implementing ideas that are based on sound evidence and that can be subjected to rigorous monitoring, evaluation and revision for adaptation to differing contexts. Yet these ideas need to be participatory, scalable and adoptable by the most victimised and marginalised groups-essentially we must establish equity through their execution. 


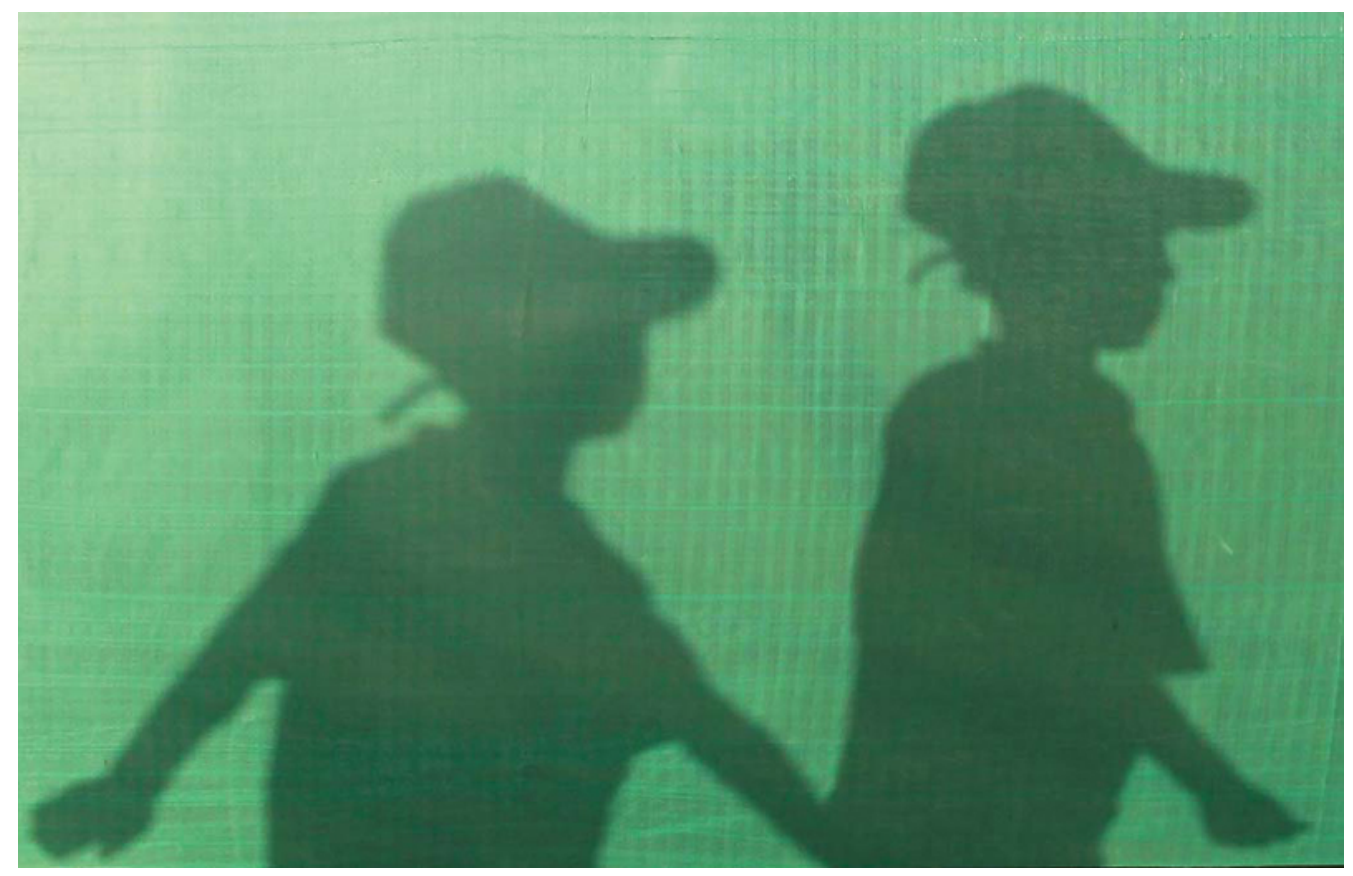

Inclusive innovation offers more sustainable development than charity and philanthropy. The development of these initiatives needs to be fostered with policy changes and a paradigm shift to integrate people's voice in the process must be ushered in. Since the success and failure of social innovation is our collective responsibility, all stakeholders should be made equally accountable for its scaling.

So, how can the corporate sector put these principles into practice? First and foremost, we need to move from corporate social responsibility and philanthropy to the much wider concept of "corporate social accountability". To be able to grow inclusively and sustainably businesses need to assess the context and identify the barriers that keep the poorest children and families from realising their rights. We need to think of measures that can be taken to engage the entire community, especially the most marginalised members, like women and children, in developing and implementing solutions.

A principled approach to innovation starts with, and is guided by, questions throughout the process-from identifying problems to developing and scaling up solutions to evaluating their impact.

How can we ensure that the poorest and most marginalised children are not excluded from such opportunities? And why should we? There is concrete evidence of the positive impact investment in children and education has on individuals, families and nations, in terms of national income, economic growth and poverty reduction, and in human development. With regard to education, the global average rate of return on investment is estimated to be around $10 \%$, whereas each additional year of education is associated with a $35 \%$ higher GDP per capita. 
On our journey to discovering, or rather creating, the answers and solutions to questions such as the one above, we will experience an ethereal joy in performing business. The same joy I feel when I see the smiling faces of children rescued from their lives of misery, poverty and captivity.

I am also seeing a large number of corporate leaders take responsibility and move from agreement to action. We are seeing the evolution of a more considerate and compassionate partnership between civil societies, governments and corporations. However, the situation of our children demands more.

Your active co-operation and participation will help build a more sustainable future. Our children are the present and the future, and we must enable them to take over the world.

This is an abridged version for print: the full article is available online at www.oecd. org/forum/oecdyearbook

Visit www.satyarthi.org

\section{References}

School of Public Health and Tropical Medicine (2015), "Final Report 2013/14, Survey Research on Child Labor in West African Cocoa Growing Areas", Tulane University. http://docplayer.net/14051853-Final-report-2013-14-surveyresearch-on-child-labor-in-west-african-cocoa-growing-areas.html 